\title{
Investigating the ratio of basal drag and driving stress in relation to bedrock topography during a melt season on Storglaciären, Sweden, using force-budget analysis
}

\author{
Jim Hedfors, ${ }^{1}$ Vingent Peyaud, ${ }^{1}$ Veijo A. POHJOla,,${ }^{1}$ Peter Jansson, ${ }^{2}$ \\ RIGKARD PETTERSSON ${ }^{2}$ \\ ${ }^{1}$ Department of Earth Sciences, Uppsala University, Villavägen 16, S-752 36 Uppsala, Sweden \\ E-mail:jim.hedfors@geo.uu.se \\ ${ }^{2}$ Department of Physical Geography and Quaternary Geology, Stockholm University, S-106 91 Stockholm, Sweden
}

\begin{abstract}
We apply the force-budget technique using the isothermal block-flow model, on Storglaciären, Sweden, to investigate the ratio between basal drag and driving stress in relation to a bedrock ridge in the bed topography during a peak melt season. The input data consist of glacier surface velocities collected using differential global positioning system surveying of a stake net and geometry from previous radar soundings and digitized ice surface maps. The study focuses on the effects of transverse bedrock ridges upon basal stress conditions. The pattern of the calculated ratio of basal drag and driving stress shows a rhy thmical position of relatively high and low basal drags on the stoss and lee sides, respectively, of the bedrock thresholds. One of the zones of low basal drag corresponds to the location where the highest basal sliding rate has been measured previously by borehode deformation studies. This zone also aligns with the area where the drainage system is suggested to change from englacial to subglacial.
\end{abstract}

\section{INTRODUGTION}

Glaciers are forced downslope by driving stress due to gravitational collapse. The driving force is opposed by frictional drag, generally between the bedrock and the ice. The balance between these forces determines the extensional and compressional behaviour of a glacier and can be described in terms of a force budget. The method of balancing forces was developed and applied by Van der Veen and Whillans (1989) and Whillans and others (1989) on Byrd Glacier, Antarctica, where they showed differences in basal drag in relation to the grounding zone of the glacier. This model has since been used successfully for various ice systems. Høydal (1996) used the force-balance technique to show that bed topography has a great influence in controlling the direction of flow, even where the ice thickness exceeds $2000 \mathrm{~m}$ (Jutulstraumen, Dronning Maud Land, Antarctica). Aided by force-budget calculations, Whillans and Van der Veen (1997) pointed out the role of lateral drag in the dynamics of Ice Stream B, Antarctica, and Price and others (2002) found that the development of streaming ice flow depends on basal conditions far upstream from the actual ice-stream onset location. Mayer and Huybrechts (1999) studied the ice-dynamic conditions across the grounding zone of Ekströmisen, East Antarctica. They found a clear transition between high and low basal drag as the ice transits from being grounded to become floating. It is clear that the analysis of force budgets provides valuable information on basal conditions for different ice systems.

Here we apply the force-budget technique, using the isothermal block-flow model, on Storglaciären, Sweden, to investigate the ratio between basal drag and driving stress, $\tau_{\mathrm{b}} / \tau_{\mathrm{d}}$, in relation to bedrock topography. This index was defined by
Mair and others (2001) while investigating the spatial patterns of glacier motion on Haut Glacier d'Arolla, Switzerland.

Storglaciären has a long history of glaciological work, and its geometrical properties are well known (e.g. Jansson, 1996), but no thorough force-balance investigation has taken place on Storglaciären in the past. However, Hooke and others (1989) studied the stress conditions and particularly the basal drag using a force balance of two small blocks of ice situated on either side of a bedrock threshold. The results from the latter study did not provide a full understanding of the dynamics across the bedrock threshold, a fact that motivated the present work.

\section{METHODS}

\section{Storglaciären and data collection}

Storglaciären (Fig. 1) is a small valley glacier in the Scandinavian mountain range, northern Sweden $\left(67^{\circ} 55^{\prime} \mathrm{N}, 18^{\circ} 35^{\prime} \mathrm{E}\right)$. The bedrock topography of Storglaciären is well known from previous radar soundings (Björnsson, 1981; Eriksson and others, 1993) providing necessary ice-depth information. Surface elevation data are from Holmund (1996). As seen in Figure la, Storglaciären consists of four overdeepenings (at $x \approx$ $22600 \mathrm{~m}, x \approx 21500 \mathrm{~m}, x \approx 20700 \mathrm{~m}$ and $x \approx 20400 \mathrm{~m}$, respectively). In our study, we will concentrate on the two overdeepenings $\left(\mathrm{OD}_{1}, x \approx 22550\right.$, and $\left.\mathrm{OD}_{2}, x \approx 22100\right)$ and the two bedrock ridges $\left(\mathrm{R}_{1}, x \approx 22800\right.$, and $\mathrm{R}_{2}, x \approx 22300$ ) closest to the terminus (Fig. 1b). The bedrock of Storglaciären consists of folded gneisses, amphibolites and diabase dykes and provides the geological control for the undulating topography (Andreasson and Gee, 1989).

Surface velocity was measured by repeated differential 

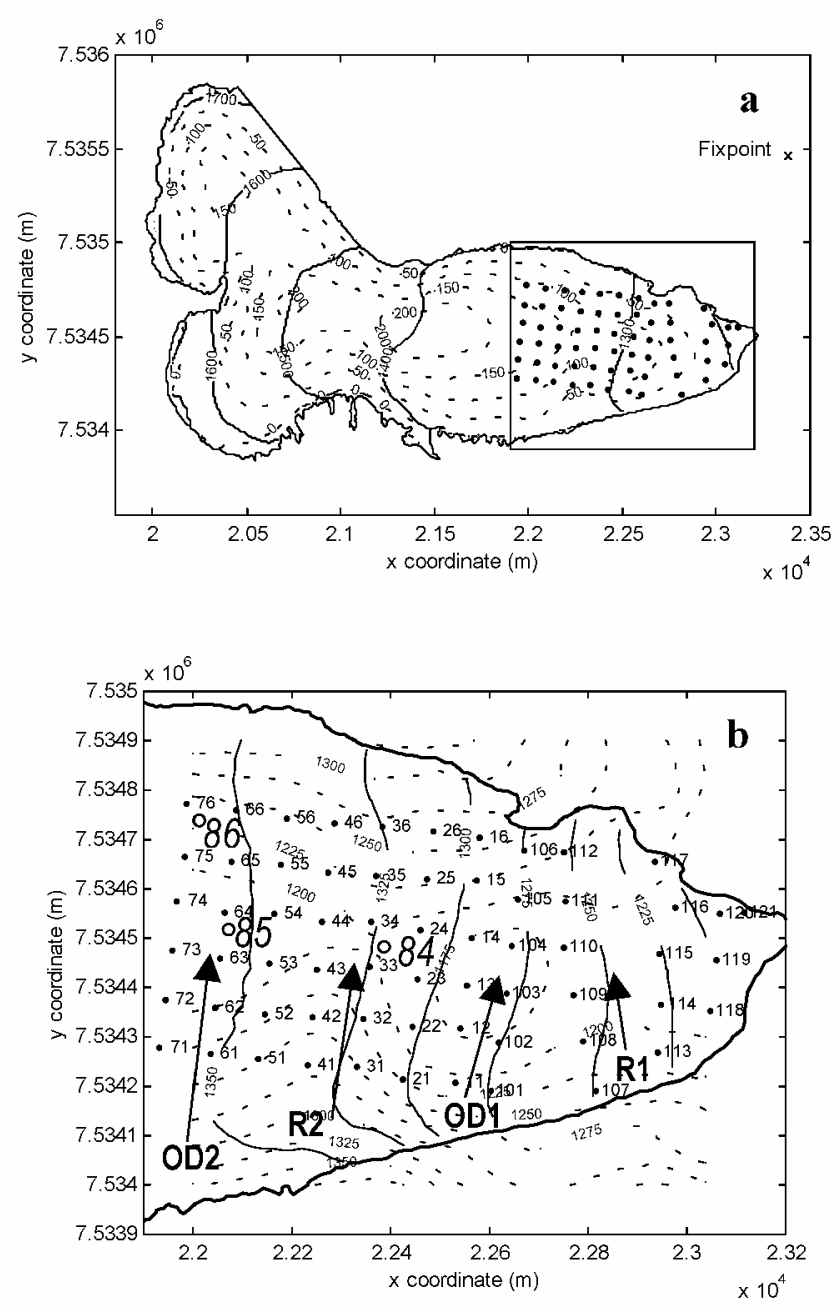

Fig. 1. Drilled and measured stake net on Storglaciären: (a) overview showing ice depth $(m)$ and surface elevation ( $m$ a.s.l.) as dashed and solid contours, respectively; ( $b$ ) subsection of area outlined with a rectangle in $(a)$, showing basal topography as dashed contours ( $m$ a.s.l.). Black dots are initial stake positions, and the fix-point is marked with $\times$ in $(a)$. Stakes are labelled in a row-column fashion from 11 to 76 and 101 to 121, as marked in ( $b$ ). The locations of the bedrock ridges are between 110 and $115\left(R_{1}\right)$ and near stake row $3\left(R_{2}\right)$ separated by the overdeepenings $\left(O D_{1}\right.$ and $O D_{2}$. Earlier borehole study sites are marked with circles accompanied by drilling year (84, 85 and 86). Coordinates are in Swedish RT 900.0 gon with the $y$ axis (south-north) perpendicular to the major ice-flow direction. The $x$ axis is aligned with the major flow direction (west-east). The grid interval is 200 (100) $\mathrm{m}$ in the $x(y)$ direction.

global positioning system (DGPS) surveying of $63, \approx 5 \mathrm{~m}$ long, aluminium stakes drilled into the glacier ice in an approximately rectangular grid of 9 by 6 elements with 9 additional stakes placed at the terminus (Fig. la and b).

Table 1. GPS campaign overview

\begin{tabular}{ccc}
\hline Measured-stake Nos. & Surveying interval & Days of separation \\
\hline $11-76$ & 17 July-6 Sept. 2000 & 52 \\
$101-112$ & 20 July-19 Aug. 2000 & 26 \\
$113-121$ & 26 July-19 Aug. 2000 & 20 \\
\hline
\end{tabular}

Stakes 100-121 were aligned roughly parallel to shear features at the glacier surface, distorting the down-glacier part of the grid. Stake grid coordinates were measured by kinematic surveying with a DGPS (Trimble 4600LS) during July-September 2000. Additional information on the GPS campaign is shown in Table 1 . A fix point located at Tarfala Research Station $(x=23378.061, y=7535465.181)$ was occupied as a base station for all measurements. All GPS data were processed at Tarfala Research Station using Trimble GPSurvey v2.35 software.

\section{Force-balance calculations}

Storglaciären is assumed to be isothermal, and the surface strain rates are assumed to be representative of those at depth. Taking resistive stresses constant with depth and neglecting vertical resistive stresses, we can write the so-called isothermal block-flow model for the horizontal directions, $x$ and $y$, as:

$$
\tau_{\mathrm{d} i}=\tau_{\mathrm{b} i}-\frac{\partial}{\partial x}\left(H R_{x i}\right)-\frac{\partial}{\partial y}\left(H R_{y i}\right), \quad(i=x, y),
$$

where the driving stress, $\tau_{\mathrm{d} i}$, is balanced by the resistive stresses, $\tau_{\mathrm{b} i}, \partial / \partial x\left(H R_{x i}\right)$ and $\partial / \partial y\left(H R_{y i}\right)$ (Van der Veen and Whillans, 1989). We will solve for basal drag, $\tau_{\mathrm{b}}$, which means the remaining terms need to be defined. The driving stress is calculated from the glacier geometry,

$$
\tau_{\mathrm{d} i}=-\rho g H \frac{\partial z}{\partial i}, \quad(i=x, y),
$$

where $\rho$ is ice density, $g$ is gravitational acceleration, $H$ is ice depth and $z$ is surface elevation. The resistive stresses are written in terms of deviatoric stresses as follows (neglecting vertical resistive stresses):

$$
\begin{aligned}
& R_{x x}=2 \sigma_{x x}^{\prime}+\sigma_{y y}^{\prime}, \\
& R_{y y}=2 \sigma_{y y}^{\prime}+\sigma_{x x}^{\prime}, \\
& R_{x y}=\sigma_{x y}^{\prime} .
\end{aligned}
$$

The constitutive relation is applied to express the resistive stresses in terms of deviatoric stresses, invoking at the same time the inverse formulation of Nye's generalization of Glen's law:

$$
\begin{aligned}
& \sigma_{x x}^{\prime}=B \dot{\varepsilon}_{x x} \dot{\varepsilon}_{\mathrm{e}}^{1 / n-1}, \\
& \sigma_{y y}^{\prime}=B \dot{\varepsilon}_{y y} \dot{\varepsilon}_{\mathrm{e}}^{1 / n-1}, \\
& \sigma_{x y}^{\prime}=B \dot{\varepsilon}_{x y} \dot{\varepsilon}_{\mathrm{e}}^{1 / n-1},
\end{aligned}
$$

where $B$ is ice viscosity and $n$ is the flow exponent for ice. The viscosity is calculated following Pohjola (1996), $\beta=\beta_{0} \exp \left(T_{0} / T\right)$, where $T$ is ice temperature, $\beta_{0}=$ $2.207 \mathrm{~Pa} \mathrm{a}^{1 / n}$ and $T_{0}=3155 \mathrm{~K}$, modified from Hooke (1981). The strain rates are obtained from the gradients in the measured glacier surface velocities, $U$ :

$$
\begin{aligned}
\dot{\varepsilon}_{x x} & =\frac{\partial U_{x}}{\partial x}, \\
\dot{\varepsilon}_{y y} & =\frac{\partial U_{y}}{\partial y}, \\
\dot{\varepsilon}_{z z} & =\frac{\partial U_{x}}{\partial x}+\frac{\partial U_{y}}{\partial y}, \\
\dot{\varepsilon}_{x y} & =\frac{1}{2}\left(\frac{\partial U_{x}}{\partial y}+\frac{\partial U_{y}}{\partial x}\right), \\
\dot{\varepsilon}_{\mathrm{e}} & =\sqrt{\frac{1}{2}\left(\varepsilon_{x x}^{2}+\varepsilon_{y y}^{2}+\varepsilon_{z z}^{2}+2 \varepsilon_{x y}^{2}\right)} .
\end{aligned}
$$

A force budget was calculated using all 63 measured 

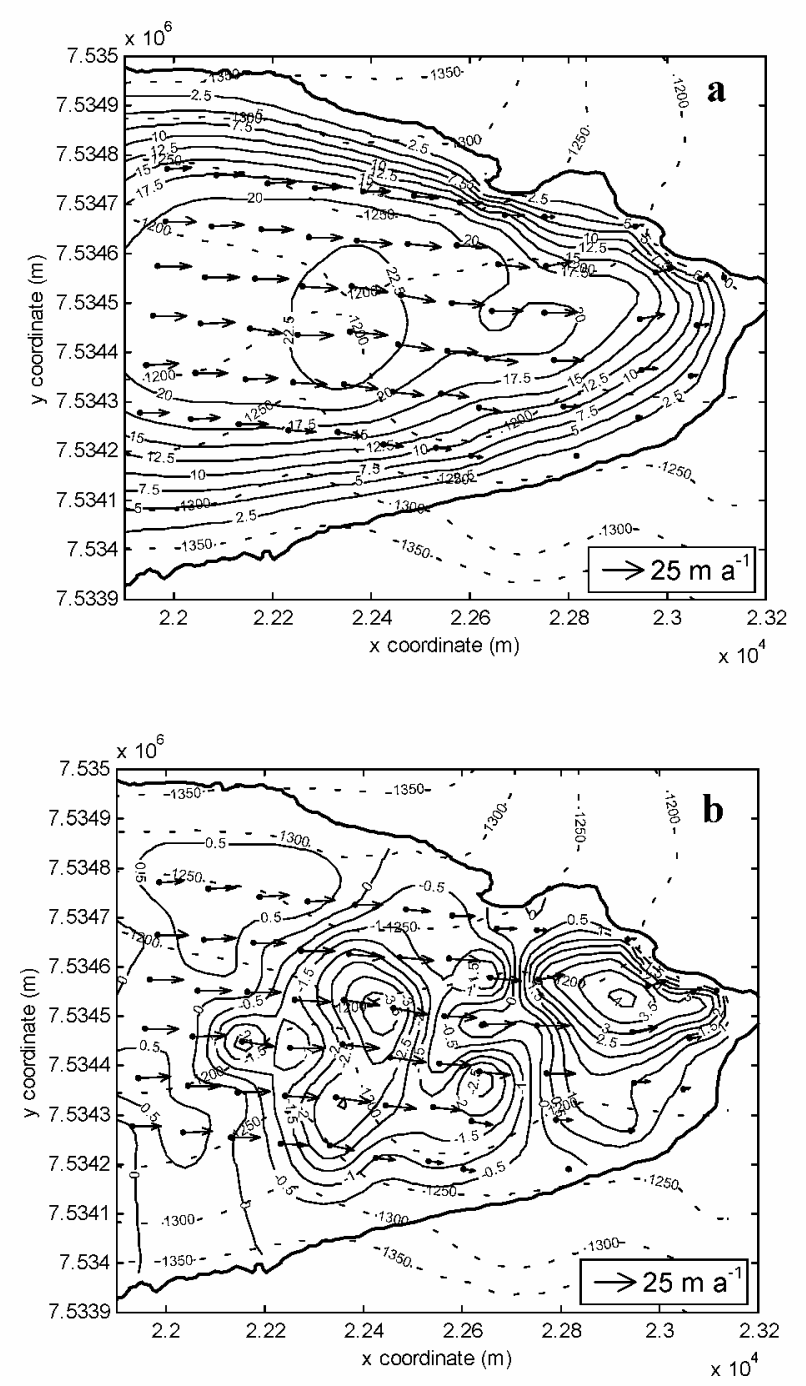

Fig. 2. Velocity fields as interpolated from GPS measurements at the glacier surface (solid contours): (a) $x$ component, $U_{x}$ $\left(m a^{-1}\right)$; and ( $\left.b\right)$ y component, $U_{y}\left(m a^{-1}\right)$. Arrows represent velocity resultants for each measured stake. Dashed contour lines are basal topography ( $m$ a.s.l.), and other map properties are as in Figure 1.

stakes, assuming they represent a period of similar surface velocities. In order to obtain better graphics for the maps of the dynamical properties, the velocity data were interpolated into a gridcell size of $20 \mathrm{~m}$. The interpolation technique used to create the grid is described in Sandwell (1987). Other constants used in the calculation are ice density, $\rho=900 \mathrm{~kg} \mathrm{~m}^{-3}$, ice temperature, $T=0^{\circ} \mathrm{C}$, ice-flow exponent, $n=3$, and gravitational acceleration, $g=9.82 \mathrm{~m} \mathrm{~s}^{-2}$.

\section{RESULTS}

A force-budget calculation yields much information on different stress components (Van der Veen and Whillans, 1989). In this work, we restrict ourselves to showing the output that is central to our discussion: measured surface velocities, $U_{i}$, driving stress, $\tau_{\mathrm{d} i}$, and basal drag, $\tau_{\mathrm{b} i}(i=x, y)$, and the in$\operatorname{dex} \tau_{\mathrm{b}} / \tau_{\mathrm{d}}$ using the resultant of $\tau_{\mathrm{b} i}$ and $\tau_{\mathrm{d} i}$.

The overall velocity pattern of the $x$ component, $U_{x}$ (Fig. $2 \mathrm{a}$ ), showing velocity increase over $\mathrm{R}_{2}$ and decrease downstream from it, agrees well with previous studies (Hooke and others, 1989, 1992). The central parts of the glacier surface show velocities $>20 \mathrm{ma}^{-1}$, with velocity maxima of
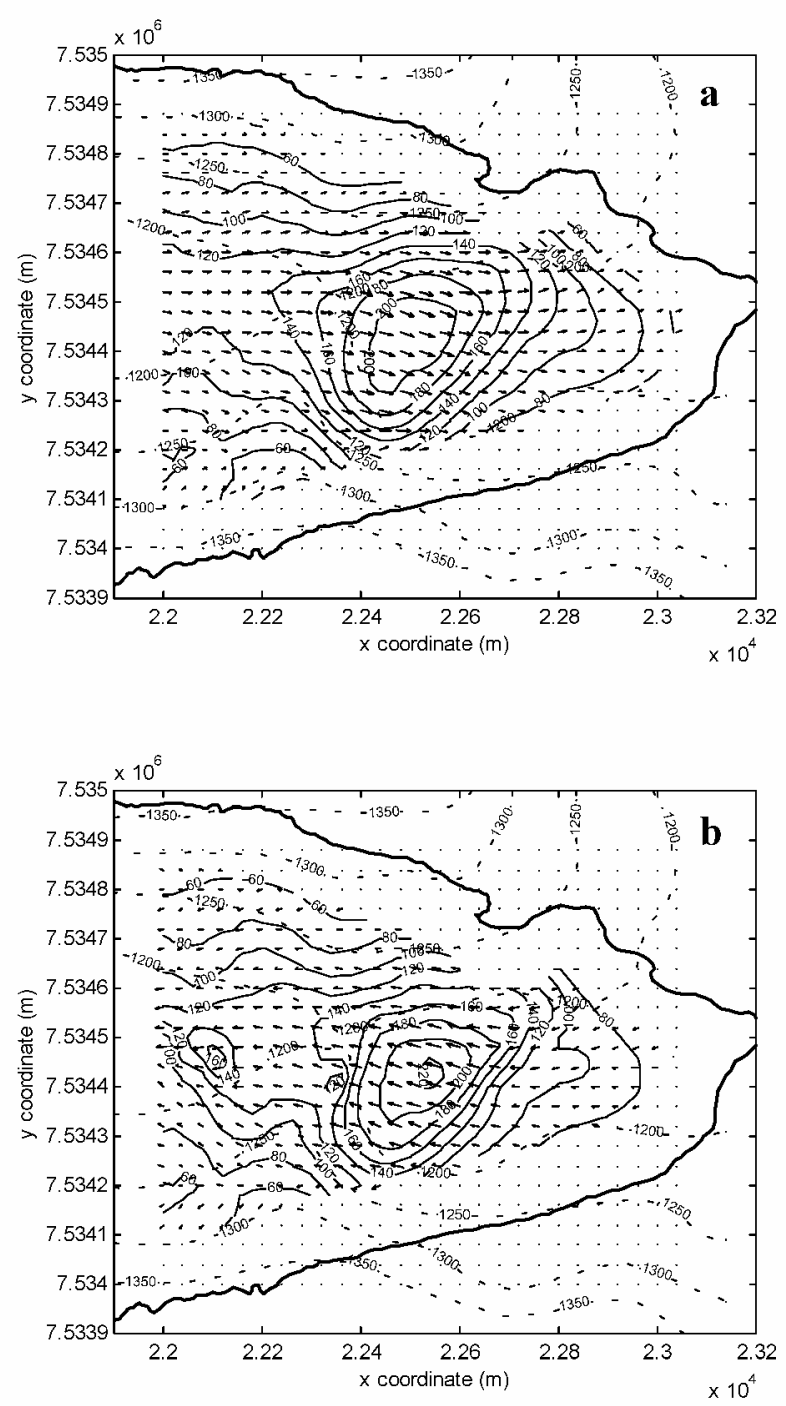

Fig. 3. (a) Calculated field of driving-stress resultants, $\tau_{\mathrm{d}}$ ( $\mathrm{kPa}$ ), at the glacier bed (solid contours). ( $b$ ) Calculated field of basal drag resultants, $\tau_{\mathrm{b}}(\mathrm{kPa}$ ), at the glacier bed ( solid contours). Arrowes form a relative representation of the $x$ and $y$ components of driving stress and basal drag in ( $a$ ) and ( $b)$, respectively. Other map properties are as in Figure 2.

$24.5 \mathrm{~m} \mathrm{a}^{-1}$ found directly over $\mathrm{R}_{2}$. The $y$ component, $U_{y}$ (Fig. 2b), of the surface velocity shows a snaking flow, where a northerly flow shifts to a southerly flow at $x \approx 22200 \mathrm{~m}$, with a shift back to northerly flow at $x \approx 22800 \mathrm{~m}$. Values range from $4.6 \mathrm{~m} \mathrm{a}^{-1}$ in a northerly direction to $3.9 \mathrm{~m} \mathrm{a}^{-1}$ in a southerly direction. This is probably due to the constriction imposed on the flow by $\mathrm{R}_{2}$ and has been recorded previously by Hooke and others (1989).

The resultant of the driving stress, $\tau_{\mathrm{d}}$ (calculated from Equation (2)), is dominated by the $x$ component (Fig. 3a) and exceeds $200 \mathrm{kPa}$ in $\mathrm{OD}_{1}$ and decreases laterally as well as longitudinally. The maximum is located over $\mathrm{OD}_{1}$ where surface slopes are steep, and where ice is locally thicker. A slight tendency for increasing driving stress is found in the upstream extension of $\mathrm{OD}_{2}$. The $y$ component of the driving stress shows relatively low negative values in $\mathrm{OD}_{1}$, which explains the turning of flow from a northerly direction above $\mathrm{R}_{2}$ into a southerly direction below $\mathrm{R}_{2}$ (Fig. $3 \mathrm{a}$ ). At $\mathrm{R}_{1}$, the driving stress forces the flow northwards once again, which is also reflected in the measured surface velocities (Fig. 2b).

The differences in the general pattern of the stress distribution and in the magnitude between the $x$ and $y$ compon- 


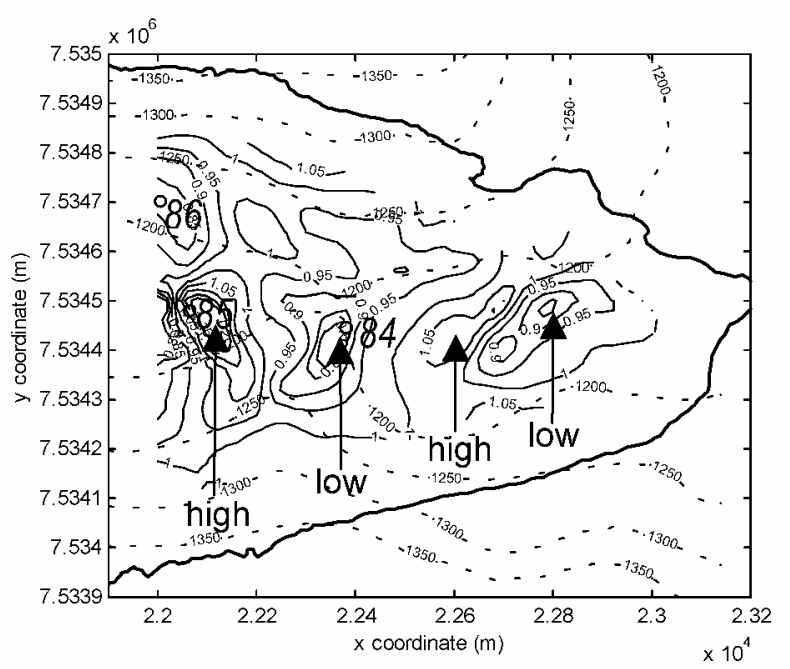

Fig. 4. The ratio of basal drag and driving stress, $\tau_{\mathrm{b}} / \tau_{\mathrm{d}}$, at the glacier bed (solid contours). Values $>1$ ( high) indicate that the basal drag exceeds the driving stress, while values $<1$ (low) indicate that the basal drag is lower than the driving stress. Earlier borehole study sites are marked with circles accompanied by drilling year (84, 85 and 86). Other map properties are as in Figure 2.

ents of basal drag $\left(\tau_{\mathrm{b} x}\right.$ and $\tau_{\mathrm{b} y}$, calculated from Equation (1)) are similar to those of the driving stress. The $x$ component reveals a zone of maximum basal drag in $\mathrm{OD}_{1}$, a local minimum on the lee side of $\mathrm{R}_{2}$ and high values in $\mathrm{OD}_{2}$ (Fig. $3 \mathrm{~b}$ ). The longitudinal basal drag decreases almost linearly from $\mathrm{R}_{1}$ towards the terminus. The $y$ component of basal drag shows high resistance to the corresponding component of driving stress (Fig. 3a). Overall, the basal drag seems to balance the driving stress in the area of $\mathrm{OD}_{1}$ and laterally in an intermediate zone between the central and the marginal parts. Close to the valley walls, driving stress is exceeded by basal drag, probably because the ice is frozen to the bedrock (Holmlund and Eriksson, 1989).

$\tau_{\mathrm{b}} / \tau_{\mathrm{d}}$ (Fig. 4) was calculated using the stress-field resultants and illustrates where the two balancing forces of basal drag and driving stress are different. The basal drag over $\mathbf{R}_{2}$, and especially on the lee side, is slightly lower (indicated as "low" in Fig. 4) than the driving stress, which explains why parts of the resisting forces must be non-local. Downslope of $\mathrm{R}_{2}$, basal drag is balanced by driving stress, while in central parts upstream of $\mathbf{R}_{2}$, basal drag exceeds the local driving stress (indicated as "high" in Fig. 4), indicating the action of non-local driving forces. Similar patterns are repeated at $\mathrm{OD}_{1}$ and $\mathrm{R}_{1}$. Hooke and others (1989) made a force-balance calculation based on six stakes between $\mathrm{R}_{2}$ and $\mathrm{OD}_{1}$ over the period July 1983-June 1985. A comparison between our results and those of Hooke and others (1989) shows similar values in these two studies. Hooke and others obtained average values for driving stress, $\tau_{\mathrm{d} x}=145 \mathrm{kPa}$, and a basal drag of 91-170 kPa over the period. This can be compared with values from our calculation, of $150-200 \mathrm{kPa}$ in the same region. Before discussing these results, we discuss the uncertainty of the data.

\section{ERRORS AND UNGERTAINTIES}

Errors in input data include measurement errors due to a combination of the human factor, instrumental faults, capacity limitations as well as missing data. Errors in the calcu- lation technique spring from uncertainties in empirically determined physical constants and assumptions in boundary conditions. The limitations of the force-balance calculation are well presented in Van der Veen and Whillans (1989). Herein we summarize the most important aspects.

The errors introduced by GPS measurements involve the instrument accuracy $( \pm 1 \mathrm{~cm})$, the tendency for stakes to shake $( \pm 0.5 \mathrm{~cm})$ at the time of measurement and the number of satellites entering the coordinate solution calculations $(<0.1 \mathrm{~cm})$. However, the long time periods over which the stakes were measured reduce the instrumental and operational errors drastically for the glacier surface deformation dataset. Over a period of 52 days (when 42 out of 63 stakes were measured) the average ice surface movement along the centre line was $3.5 \mathrm{~m}$, giving a maximum measurement error of $0.91 \%(2 \times 0.016 / 3.5)$ or $0.22 \mathrm{~m} \mathrm{a}^{-1}$. A rough estimation of the errors in the longitudinal strain rates (calculated over the stake grid size of $100 \mathrm{~m}$ ) gives $0.0022 \mathrm{a}^{-1}\left(0.22 \mathrm{~m} \mathrm{a}^{-1} / 100 \mathrm{~m}\right)$ which is about $20 \%$ of the calculated strain rates in the area of interest.

The ice-depth information is most reliable at the centre line of the glacier, while, moving towards the margins, the risk of disturbed reflections reduces the quality of the data. A maximum error of $\pm 5 \mathrm{~m}$ is assumed, although this is systematic and does not affect slope gradients to a large extent. The assumption of a $0^{\circ} \mathrm{C}$ ice temperature is correct for most of the glacier depth profile, but Hooke and others (1983), Holmlund and Eriksson (1989) and R. Pettersson (unpublished information) have shown the presence of a cold surface layer $(<60 \mathrm{~m})$ that affects the values of the dynamical parameters. Consequently, this cold surface layer possesses a higher viscosity, causing the ice to deform more slowly than the underlying temperate ice. Setting the ice temperature of the whole ice body to $-4^{\circ} \mathrm{C}$, the resulting basal drag field equals the basal drag field based on a temperature of $0^{\circ} \mathrm{C}$. However, small differences of up to $\pm 10 \mathrm{kPa}$ appear near $\mathrm{R}_{1}$ and $\mathrm{R}_{2}$. The overall dynamical pattern does not appear different because of this.

In our calculation, we used a higher-density grid resolution than that of the measured stakes. The purpose of this was to obtain a better visualization in the output graphics of the strain and stress fields across the whole investigated ice body. A test run with a grid resolution equal to that of the actual measurement data, $100 \times 100 \mathrm{~m}$, was performed only to show the same patterns and magnitudes at that coarser spatial scale.

\section{DISGUSSION}

The force-balance calculation shows a repetitive pattern in $\tau_{\mathrm{b}} / \tau_{\mathrm{d}}$ as the ice flows over the bedrock ridges and into overdeepenings. This pattern is visible in Figure 4, and shows a rhythmical position of relatively high and low basal drags on the stoss and lee sides, respectively, of the bedrock thresholds. The wavelength of these relatively evenly distributed highs and lows is $\sim 400 \mathrm{~m}$. Judging from the force-balance results, we find generally stickier basal conditions on the stoss side of the thresholds, and more lubricated conditions on the top and lee sides of the ridges. Ice flow is compressive upstream of the sticky areas, while flow is extensional between sticky and better-lubricated areas (not shown). The shift from compressional to extensional longitudinal strain is easily understood from continuum flow mechanics, where ice needs to accelerate when it moves from a stickier area to a more lubricated zone. The position of the centres of 
maximum extension found on the stoss sides of the ridges suggests that the acceleration of ice over bedrock ridges develops to compensate for decreased cross-sectional area, hence maintaining constant flux of ice. The accumulated force from ice upstream provides the driving force for the acceleration over the bedrock ridge.

We use the deformation of the surface area to find the stress pattern at the bed, but the englacial deformation pattern is an unknown (Van der Veen and Whillans, 1989). Hooke and others $(1987,1992)$ investigated the englacial deformation patterns, or longitudinal and transverse vertical strain distribution $\left(\dot{\varepsilon}_{x z}, \dot{\varepsilon}_{y z}\right)$, where Hooke and others (1987) studied borehole deformation during July-September 1984 (borehole 84 in Fig. 1b) downstream of $\mathrm{R}_{2}$ at a point between our stakes 24 and 33. Hooke and others (1992) studied borehole deformation during July-September 1985 (borehole 85 in Fig. 1b) upstream of $R_{2}$ at a point between our stakes 63 and 64 . They also studied two boreholes in 1987 and 1988, respectively, in more lateral positions upstream of the area investigated in this work. An additional borehole (borehole 86 in Fig. 1b) was studied near stake 76 , but results from this borehole were never published.

The general pattern from these studies was a higher component of basal sliding at the centre-line boreholes $(>81 \%$ of surface velocity) than at the more lateral boreholes measured in 1987 and 1988 (generally 60-75\% of surface velocity). This is in accordance with our estimates of basal friction (Figs $3 \mathrm{~b}$ and 4), where basal drag is higher than driving stress at the glacier margins. The reason for the apparent increased lubrication at the centre of the glacier is that the lateral part is frozen to the bedrock, by higher water pressures at the centre and perhaps thicker till layers at the centre of the glacier. However, the results from till-deformation studies beneath Storglaciären (e.g. Iverson and others, 1995) indicate that the till does not play an active role in the flow of the glacier. Hence, till deformation mechanisms can be ruled out in this case.

Boreholes 84 and 85, drilled on each side of $\mathrm{R}_{2}$, may help us to understand the basal dynamics at the bedrock ridge. A period of extrusion flow was identified in borehole 84 over part of the high-melt season (July) (Hooke and others, 1987), with basal velocities up to six times higher than surface velocities. Hooke and others (1987) suggested that decoupling of the ice from the bed by increased basal cavities filled with overpressurized water (i.e. decreased basal drag) may explain the episodic extrusion flow. No extrusion flow was found in borehole 85 (Hooke and others, 1992). When we compare the studies of internal deformation to our forcebudget results, we find that borehole 85 was placed over an area of high basal drag, and that borehole 84 was placed over an area of low basal drag. Similarly, the area centred on borehole 86 showed episodic extrusion flow. Hence, it is likely that the episodic extrusion flow in borehole 84 was caused by the low basal drag on the lee side of the threshold. This can also be seen as a higher fraction of internal deformation in borehole 85 (82\% basal sliding) compared to borehole 84 exhibiting about $92 \%$ basal sliding in two survey periods of non-extrusion flow during late summer. The cause of extrusion flow in borehole 86 cannot be described in terms of lee from any ridge, since it was measured upstream of $R_{2}$. The position in the area of decreased basal drag is, however, similar to that of borehole 84 .

The different studies referred to here were performed in different years but at roughly the same time of year. The velocity variations on Storglaciären show a relatively similar pattern from year to year (Hooke and others, 1989; Jansson, 1995); hence, comparisons from year to year, especially when considering longer-term averages, are largely non-controversial. It is possible that the patterns revealed by the force budget vary with time, but we assume that the pattern is consistent from year to year, with larger intraannual variation. The bedrock topography and ice thickness are the major parameters that determine the pattern, and these are stable on a longer time-scale than is necessary for this study. Also, studies of the intra-annual variation in the basal drag pattern have shown that the wavelength of the pattern shown in Figure 6 is persistent within the year, but the amplitude varies with the seasons (Hedfors, 2002).

This force-budget analysis shows that the ice acceleration across $R_{2}$ is induced by raised stresses on the stoss side and governed by low basal drags on the lee side. Low friction between the ice and underlying bedrock or till may develop as a result of intensive lubrication (Iverson and others, 1995). Jansson (1997) pointed out that the hydrological drainage pattern changes from englacial upstream of $\mathrm{R}_{2}$ to subglacial on the down-glacier side. This would explain the development of a local "slippery spot" downstream of $\mathrm{R}_{2}$ found in this study, suggesting a "pulling" of ice over the ridge.

Use of the isothermal block-flow model has proven valuable in the search for stress conditions underneath Storglaciären. Most interesting is the relative pattern of the stress components; less important are their exact magnitudes. The major drawback of the model is that the viscous terms tend to be overestimated (since surface values are applied to the entire glacier thickness), so that basal drag becomes overestimated as well. Another extreme can be found when basal drag is set equal to driving stress. Hence, the actual value for basal drag may be expected to fall between these two set-ups. In the case of Storglaciären, it is assumed that the isothermal model represents the actual environment since the obtained stress distributions strongly reflect the underlying bedrock topography. Also, consider that:

(i) repeated calculations for several datasets of surface velocity, covering different time periods, show similar stress distributions (with minor interesting differences; Hedfors, 2002);

(ii) high values of $\tau_{\mathrm{b}} / \tau_{\mathrm{d}}$ are found towards the valley walls where the glacier is frozen to the bed (Pohjola, 1993);

(iii) areas of low values of $\tau_{\mathrm{b}} / \tau_{\mathrm{d}}$ align well with areas where the highest rates of basal sliding have been measured (Hooke and others, 1987); and

(iv) the minima in the calculated $\tau_{\mathrm{b}} / \tau_{\mathrm{d}}$ are found in an area where the water-drainage system changes from englacial to subglacial (Jansson, 1997).

These facts help to establish confidence in the datacollection technique used, as well as in the force-budget method as applied to a small valley glacier.

\section{GONGLUSION}

The force-balance calculation shows a repetitive pattern in $\tau_{\mathrm{b}} / \tau_{\mathrm{d}}$ as the ice flows over the bedrock ridges and into overdeepenings. Basal conditions are generally found to be stickier on the stoss side of the thresholds, and more lubricated on the top and lee sides of the ridges. When we compare the 
studies of internal deformation to our force-budget results, we find that borehole 85 was placed over an area of high basal drag and that borehole 84 was placed over an area of low basal drag. The lowest values of $\tau_{\mathrm{b}} / \tau_{\mathrm{d}}$ are found over $\mathrm{R}_{1}$ which corresponds to the location where the water-drainage system changes from englacial to subglacial. The results from this study help to establish confidence in the force-budget method as applied to a small valley glacier.

\section{AGKNOWLEDGEMENTS}

A number of people at the Tarfala Research Station helped to collect and process the data, as well as being resourceful in solving logistical problems. We thank them for their contribution to this work. The whole project was graciously funded by a grant to J.H. from the Swedish Society for Anthropology and Geography (SSAG) and to P.J. from the Swedish Research Council (VR). The comments of R. G. A. Hindmarsh and two anonymous referees helped to improve this paper.

\section{REFERENGES}

Andréasson, P.-G. and D. Gee. 1989. Bedrock geology and morphology of the Tarfala area. Geogr. Ann., 71A(3-4), 235-239.

Björnsson, H. 1981. Radio-echo sounding maps of Storglaciären, Isfallsglaciären and Rabots glaciär, northern Sweden. Geogr. Ann., 63A(3-4), 225-231.

Eriksson, M., H. Björnsson, U. C. Herzfeld and P. Holmlund. 1993. The bottom topography of Storglaciären: a new map based on old and new ice depth measurements, analyzed with geostatistical methods. Stockholm, Stockholm University. Department of Physical Geography. (Forskningsrapportserien STOU-NG 95.)

Hedfors, J. R. 2002. Investigations of ice flow in polar regions. (Licentiate thesis, Uppsala University.)

Holmlund, P. 1996. Maps of Storglaciären and their use in glacier monitoring studies. Geogr. Ann., 78A(2-3), 193-196.

Holmlund, P. and M. Eriksson. 1989. The cold surface layer on Storglaciären. Geogr. Ann., 71A(3-4), 241-244.

Hooke, R. LeB. 1981. Flow law for polycrystalline ice in glaciers: comparison of theoretical predictions, laboratory data, and field measurements. Rev. Geophys. Space Phys., 19(4), 664-672.
Hooke, R. LeB. 1998. Principles of glacier mechanics. Upper Saddle River, NJ, Prentice Hall.

Hooke, R. LeB., J. E. Gould and J. Brzozowski. 1983. Near-surface temperatures near and below the equilibrium line on polar and subpolar glaciers. Z. Gletscherkd. Glazialgeol., 19(1), 1-25.

Hooke, R. LeB., P. Holmlund and N. R. Iverson. 1987. Extrusion flow demonstrated by bore-hole deformation measurements over a riegel, Storglaciären, Sweden. f. Glaciol., 33(113), 72-78.

Hooke, R. LeB., P. Calla, P. Holmlund, M. Nilsson and A. Stroeven. 1989. A 3 year record of seasonal variations in surface velocity, Storglaciären, Sweden. 7. Glaciol., 35(120), 235-247.

Hooke, R. LeB., V. A. Pohjola, P. Jansson and J. Kohler. 1992. Intra-seasonal changes in deformation profiles revealed by borehole studies, Storglaciären, Sweden. F. Glaciol., 38(130), 348-358.

Hø̈ydal, Ø. A. 1996. A force-balance study of ice flow and basal conditions of Jutulstraumen, Antarctica. F. Glaciol., 42(142), 413-425.

Iverson, N.R., B. Hanson, R.LeB. Hooke and P. Jansson. 1995. Flow mechanism of glaciers on soft beds. Science, 267(5194), 80-81.

Jansson, P. 1995. Water pressure and basal sliding on Storglaciären, northern Sweden. 7. Glaciol., 41 (138), 232-240.

Jansson, P. 1996. Dynamics and hydrology of a small polythermal valley glacier. Geogr. Ann., 78A(2-3), 171-180.

Jansson, P. 1997. Longitudinal coupling in ice flow across a subglacial ridge. Ann. Glaciol., 24, 169-174.

Mair, D., P. Nienow, I. Willis and M. Sharp. 2001. Spatial patterns of glacier motion during a high-velocity event: Haut Glacier d'Arolla, Switzerland. F. Glaciol., 47(156), 9-20.

Mayer, C. and P. Huybrechts. 1999. Ice-dynamic conditions across the grounding zone, Ekströmisen, East Antarctica. 7. Glaciol., 45(150), 384-393.

Pohjola, V. A. 1993. Ice dynamical studies on Storglaciären. (Ph.D. thesis, Uppsala University.)

Pohjola, V. A. 1996. Simulation of particle paths and deformation of ice structures along a flow-line on Storglaciären, Sweden. Geogr. Ann., 78A $(2-3)$, 181-192.

Sandwell, D. T. 1987. Biharmonic spline interpolation of GEOS-3 and SEASAT altimeter data. Geophys. Res. Lett., 2, 139-142.

Van der Veen, C. J. and I. M. Whillans. 1989. Force budget: I. Theory and numerical methods. F. Glaciol., 35(119), 53-60.

Whillans, I. M. and C. J. van der Veen. 1997. The role of lateral drag in the dynamics of Ice Stream B, Antarctica. F. Glaciol., 43(144), 231-237.

Whillans, I. M., Y. H. Chen, C. J. van der Veen and T. J. Hughes. 1989. Force budget: III. Application to three-dimensional flow of Byrd Glacier, Antarctica. F. Glaciol., 35(119), 68-80. 